\title{
In and Out of Place: Site-based Screendance
}

\author{
Kyra Norman
}

et's begin by standing. Standing in the space. Focus for a moment on your breath. Its pace, its rhythm, its movement. Not changing anything, just noticing. The ground, gravity, weight, balance. Sounds, impulses, the sensations of the skin, the feel of the floor, and the fabric of your clothes. Now take this awareness further out, into the space around you. What do you notice?

When I prepare to dance, I prepare to see differently; to see space differently, shaped through an attention to how I experience this space physically. Exploring the role of the body in our perception of space leads us into rich areas of thought and action: from cognitive sciences to phenomenology and Merleau-Ponty, for whom "the perceiving mind is an incarnated mind,"(3)' from somatic practices in dance to Laura U. Marks' writing in the field of criticism, through which she works "to restore a flow between the haptic and the optical that our culture is currently lacking (xiii)."2 In preparing this paper, I have drawn particularly on writing by John Berger, Lucy Lippard, Gaston Bachelard, Tim Ingold, Miranda Tufnell and Chris Crickmay. I have woven a few threads of their texts into what follows, but these are only traces, and I warmly recommend reading these writers for a far more thorough discussion of their ideas.

It seems important to acknowledge at the outset that this paper can only scratch the surface, make a start, in looking at screendance and space, place, and site. Through this writing I hope to raise questions and provoke dialogue as to how we might further explore these issues in theory and in practice. I write from the perspective of an artist and researcher working within the field of screendance in the UK, and my intention here is to invite reflection on current thinking and practice in this field.

In his book, Ways of Seeing, John Berger writes of the activity of vision, a succinct reminder of the physical engagement that frames what and how we see. Berger writes:

We only see what we look at. To look is an act of choice. As a result of this act, what we see is brought within our reach - though not necessarily within arm's reach. To touch something is to situate oneself in relation to it. ... We never look at just one thing; we are always looking at the relation between things and ourselves. Our vision is continually active, continually moving, continually holding things in a circle around itself, constituting what is present to us as we are. (8) 3

Our sense of space begins in our own body: begins with, as dance artist Lisa Nelson has described it, "the body as both proscenium and performer,"4 simultaneously contextualising and enacting, framing and doing. Our perception of space-scale, symmetry, distance, texture, temperature-is informed directly by our own physicality. As MerleauPonty writes, "spatial forms or distances are not so much relations between different points in objective space as they are relations between these points and a central perspective — our body" (5). Through studio practice, dancers - and particularly those working with improvisation - draw on this experience to inform being in relation to space, allowing the space to invite action (or inaction). In this paper, my interest lies in what happens when 
dance-trained artists bring this physical engagement with space, and ways of seeing, to making work for the spaces of the screen. ${ }^{5}$

Screendances create, encounter, and are read through layers of space. We might include here the architectural, social spaces of the shoot and of the screening, the various spaces created by the camera and through the edit, the spaces of and between bodies. All of these spaces are contained within the space of the screen but as artists and as audience, we may pay more or less attention to each layer of space at different points and in different works.

In his essay, "Video Space: A Site for Choreography", Douglas Rosenberg observes that "video dance is a site-specific practice, that site being video itself ... This is where the work occurs and it is further the architecture against and through which the audience perceives the work. . . Site provides context" $(1,5) .{ }^{6}$ Rosenberg explains that he uses 'video' in this context as shorthand, encompassing the various processes of video production, including recording, transmission, and reception. Such a concept of site, unfolding through time, rather than being a fixed point in space, lends itself to a consideration of process-the work occurs in the camera, in the edit, as well as on the screen. Where terms such as 'cine-dance', 'dance film,' and 'video dance' have sought to categorize dance and moving image work through an attention to medium, the term 'screendance' brings all manner of screen media together, foregrounding the site and surface of the screen.

The screen is a site in the way Rosenberg speaks of video as site-a collection of processes, languages, and histories. This includes, but is not limited to, cinema, video art, television, computer gaming, and the Internet. It is also a recognizable site in spatial terms, and such a focus on space refers us back to the body and particularly to our own embodied experience of space. Having dealt a little with the 'screen' in 'screendance', it seems worth mentioning the 'dance' also. I am proposing here that dance is more than the subject of the screen work, it may also be a means of approaching, exploring and articulating screen space: bringing with it its own collection of processes, languages and histories.

In a moment, I will move from the general to the particular, and turn to three examples of artists whose work I see as doing just this: Angela Praed, Shahar Dor \& Amit Shalev, and Becky Edmunds. I will suggest that these artists draw on both dance-in particular site-based performance making — and screen processes and conventions, engaging in a practice that requires them to be both 'in and out of place.' By this I mean that, firstly, it is through a sincere attention to place in the moment of recording that the substance of the work arises; at the same time, this material is being shaped by an awareness of the space of the screen and a projection into the future, toward the edit, that screen space, and the future viewer. And, whilst these works may usefully be read through various screen lenses (e.g. documentary, documentation, video art) I will propose that the approach to place and space evidenced in these works is distinctive of a rich seam of improvised site-specific performance making, which can be traced through the history of dance, and leads us to significant questions about the exhibition and discussion of screendance.

First though, I will briefly address the way in which I am using the term 'place' in this writing. In his wide-ranging history of the line, anthropologist Tim Ingold contrasts "the line that goes out for a walk" in Paul Klee's terms — freewheeling, expressive and born of movement-with the geometric model of nodes and connecting lines that maps the modern world and is most often used to shape our understanding of transport and urban planning 
(72-84). ${ }^{7}$ The latter model brings to my mind the map of the London Underground: visually bold and coherent in overview but bearing little resemblance to the experience of navigating between these points at ground level.

I introduce this idea here because Ingold uses these contrasting lines to propose two distinctive ways of visualising place, in each case with significant implications for perception, movement, and the body. The first represents place with a hub-and-spokes model —each place is a clearly defined circle, from which radiate lines representing distinct travel routes or pathways. People are represented by dots, contained within a particular circle. The second model imagines place as a knot, made up of lines that represent the lifelines of each inhabitant, "bound together in the knot, but . . not bound by it" (Ingold 100). In an era characterized by movement, travel and change, it seems useful to conceive of place in this second way: as created by people crossing paths; but this crossing of paths need not imply constant motion, one can choose to remain, linger, dwell. I have kept this image of place in mind whilst thinking about the works discussed below.

Lastly, before turning to my three examples, I would like to, again, briefly, discuss the way in which, as a way into reading particular works, an attention to the layers of space that run through screendance offers an alternative means of grouping works together, placing them in dialogue with one another, and allowing us to interrogate screendance as an art form. For example, Harmony Bench's paper at OpenSource \{VideoDance\} (OSVD), in 2007, discussed a range of works created variously for cinema, television, installation and online viewing — set in what Bench described as 'no-place'-works where bodies seem to be suspended in, usually black or white, 'empty' space. Bench describes these "antigravitational choreographies [as] dance-based strategies of mobility developing alongside globalized imaginings of space, ground and body" (124). In the discussion following this paper, participants in OSVD talked about the way in which the bodies in many of these works seemed to lack not only physical gravity but also the gravity of memory. This came back to me recently when reading Lucy Lippard's The Lure of the Local, in which she proposes that "space defines landscape, where space combined with memory defines place" (281). ${ }^{9}$ Without memory, these bodies are out of place.

In screen terms, the 'no-place' Bench identifies is familiar to filmmakers as 'limbo.' It usually entails shooting in a blacked-out studio, with lighting arranged to create an impression of boundless space, without horizon. It seems important too that no-place alters sound-either amplifying it, distorting it, or cutting it out altogether. Sound colors our vision and shapes our perception of what we see as well as hear, and atmospheric sound contributes to the reading of place on screen. In an essay entitled "Losing Your Place," written as part of the work of Common Ground, Sue Clifford and Angela King describe the collection of atmospheric sound on a film shoot: "that elusive particularity, so often undervalued as 'background noise,' is as important as the stars" (7). ${ }^{10}$

So what of works that begin 'someplace,' then? Since this is an argument for particularity, let's look to the particular. "Place-specific (as opposed to drive-by) art begins with looking around" (Lippard 281).

In 2004, choreographer Angela Praed and dancers Robert Mennear and Lois Taylor undertook a dance research project, We're All The Same Height Lying Down, touring a 40-minute duet around the bedrooms of members of the public who had replied to their advertisement in a local paper, in Cornwall, where they live. Working in collaboration with Laura and David 
Travail, Praed subsequently produced the 12-minute documentary, The Bedroom Tour. Whilst each performance was witnessed only by a handful of people, in each case invited by the host and restricted in number by the intimate performance space, the documentary went on to be screened widely, including being shortlisted for the IMZ dance-screen documentary award in 2005. I am interested in what happens through this shift in context and conventions from live performance to screen, working into and out of place.

The choreographed performance, a dance duet between a young man and an older woman, takes place on the bed in each of the hosts' homes. We see recorded extracts in the video. It has been created for 'the bedroom' as a culturally specific, imagined location, and it is the hosts' homes and anecdotes that create the actual 'place' for the performance, coloring our reading of the performance on screen with intimate local detail and texture. Their responses to the performance are given time to unfold on screen. One host reminisces about her bed's construction by herself and friends, as students in the 1970s, from a pattern in Reader's Digest. Another talks about the contrast between his orderly work life and chaotic home life-with comic timing, at this point, and mid-sentence, the light cuts out (we presume a fuse or bulb has blown) and the scene is cast into darkness and laughter.

We see that each of the hosts reads the live work very differently, and their readings color our own. In this way, the performance of the set choreography, live before an audience, becomes an element in a highly complex work for the screen that includes the actions and opinions of the hosts as both audience and protagonists - their contextualization of the dancing they witness adds rich layers of ambiguity and narrative. The domestic setting frees the hosts' imaginations - one of the hosts is explicit in stating that whilst she has found this experience fulfilling and nourishing, it has not made her any more likely to visit a theatre. As Bachelard writes, "the house shelters daydreaming, the house protects the dreamer, the house allows one to dream in peace" (6). ${ }^{11}$ In the transformation to screen space, this shelter is lost, the dreamers exposed. Is a new form of shelter constructed through the adherence to documentary conventions, framing the hosts as characters in this new work? What is the responsibility of the artist to the live audience in the screen work, and to the screen audience?

Such questions are of a piece with Praed's original and sustained exploration around the role of the audience in site-specific performance and work for the screen. It is also in keeping with the screen conventions through which work is framed: that of a television documentary. The Bedroom Tour uses documentary as a framework to reflect on particular embodied experiences, documenting responses and memories-of the choreographer, performers and hosts - as much as the performance itself. In so doing, this process inevitably shapes these responses and memories. The use of camera, editing, location and speech presents the work in a style that is familiar from television documentary, bringing the live performance, with its theatrical conventions unfamiliar to the hosts, back into focus through a framework familiar from their own front rooms. In this way, the live work created for the specific site of people's homes becomes a work for the specific site of the screen.

To move now from Cornwall to Tel Aviv, to switch our gaze from rural and suburban houses to city streets. Lippard writes that "looking around in a city is visual overload. . . . Impressions are confused and chaotic. Longtime residents rushing here and there often forget to look at their surroundings while newcomers and visitors get lost and overwhelmed" (Lippard 197). 
Movement and performance artist Shahar Dor and cinematographer Amit Shalev together have developed a practice they call "Improvideo." They subtitle this process, "Spontaneous Dialogue." An improvisation-based method that aims to realize on film/ video compositions of performer, camera, and space, they describe their work as "a heightened interdisciplinary model that engages with questions around the body, performance, image creation, space and audience."12 I will use as examples here two works, No Conflict and John's Shoe, both made in their hometown of Tel Aviv.

No Conflict begins in motion, performer and camera walking down the street side by side. It is a city street scene; we see other people pass by, traffic, and shops. There are cuts, but the leisurely series of shots has the feeling of continuity, scenes from a single journey. Performer and camera vary their speed, sometimes one ahead, sometimes the other. They pass a boarded-up building covered in fly posters; the performer picks up and expands on movement material found in an image on one of the posters. The performer moves on, slipping between gates drawn nearly closed; the camera waits on the street side of the gates but through the narrow gap we have a sense of wider space, a parking lot, or a gap where a building used to be. The camera's view is restricted, whilst the performer has more room for maneuver.

When the performer opens wide the gate, he seems to invite the camera into the space, and the camera moves in. The two develop a duet of movement and rest, sometimes these states coincide; sometimes the camera moves past a stilled performer, sometimes the camera's gaze rests upon the travelling performer who then moves out of shot. In this space, there is no one else. Staying for a while in one place gives us time to register what we are seeing and to begin to see particularity rather than simply the idea of a city. As Lippard writes, "the light, the climate, the style, the materials, the flora and fauna (or lack thereof), the spaces and proportions, not to mention the demography and population, make cities and their neighbourhoods unique" (197). The performer leaves through the gate, and then the camera follows. They move off together back out into the street, and continue their walk, the performer's movement now interspersed with moments and qualities from the freer movement experienced in the enclosure. The camera moves in front of the performer, the footage slows, the screen fades to black.

John's Shoe begins with the performer side-on to the camera, sitting in the back seat of a parked car, door open, feet on the road, tying a shoelace. The opening sequence continues in short close-ups, cut together: the performer's face leaning down, filling the upper half of the screen, the hands on the shoelace. The camera then cuts further away to reveal the parked car's place on a residential city street, and the performer standing in the center of the shot, then walking out and away. Again, the performer and camera take a walk but this time the feel is more of montage, and as viewers we connect disparate places into one journey, rather than being shown the routes between them. Again, the performance opens out into a sort of 'clearing', this time a deserted sports ground, and the performer and camera develop a duet which seems to be led by a spirit of enquiry, the performer exploring and finding places to rest in the space, the camera exploring the body moving in space and finding moments to allow the gaze to alight, to come to rest.

Through a quick series of shots, we travel from this sports ground, back to the street, to the threshold of an apartment building with its double doors of glass bricks and come to rest once again in an overhead shot of a tree. The camera is static for some time as the performer 
circles and spirals around the tree, before adding a secondary layer of circling through a series of moving shots, tracking around the action in circles, sometimes travelling at the same speed and in the same direction as the performer and sometimes differently. A few more short, cross-faded shots take us out of this courtyard, out of the house to find the performer sitting on a wall, playing with his broken shoe. The sole comes loose, comes away and becomes almost a second character in front of the camera in an action-reaction shot sequence, then is chased up and down the curb, becoming an imprint, like the drawn footprints teaching a sequence of dance steps, an obstacle, a magnet, a toy: the scene cuts to black.

Merleau-Ponty writes:

We grasp external space through our bodily situation... Our body is not in space like things; it inhabits or haunts space. It applies itself to space like a hand to an instrument, and when we wish to move it about we do not move the body as we move an object. We transport it without instruments as if by magic, since it is ours and because through it we have direct access to space. For us the body is much more than an instrument or a means; it is our expression in the world, the visible form of our intentions. (5)

In both works, Dor and Shalev create duets between camera and performer, which open up the spaces they explore to the viewer. The body and the instrument work together to make visible the form of their shared intentions as they unfold. Berger writes that "soon after we can see, we are aware that we can also be seen. The eye of the other combines with our own eye to make it fully credible that we are part of the visible world" (9). Dor and Shalev fold this reciprocal act of vision into their process, and in so doing draw our attention to our own active vision in relation to the work.

Both artists take on the role of defining the performance space: sometimes Shalev frames space in a particular way and Dor fits his performance into this; sometimes Dor demarcates a particular space through his performance and Shalev fits his camerawork to that. In each case, the particularity of place sets the scene for action, and this action is simultaneously shaped by an anticipation of the screened image. Their, and our, attention moves in and out of place.

In The Poetics of Space, Gaston Bachelard writes that "space calls for action, and before action, the imagination is at work" (12). In improvisation, as here, the imagination is at work through action, rather than beforehand. It is this engagement with embodied, active imagination —instant composition — that improvisation brings to the screen. This composition comes from the body and its responsiveness to place. As director and choreographer Angus Balbernie writes, "the tuned body-in-landscape creates, and is offered, a resonant and responsive connection to core perceptual systems and expressive activity."13

In an interview with Chirstinn Whyte for Filmwaves, Becky Edmunds suggests that place has a very direct effect on her camera work. Where the built-up, densely populated SouthEast of England found her "addicted to close-up,"14 her experience of vastness in Argentina and subsequently Swedish Lapland invited a new way of working, a new interest in the use of extreme wide shots, and long takes. The outcomes of these instincts create works that, whilst visually and kinetically very different, are connected through their beginning in the body and its response to the particularity of place. These works are also about time: the artist taking time to experience place; the viewer taking time for the work to unfold. Edmunds has said: 
It is interesting that there are some technical decisions that working out in the landscape leads me to. I keep working with the zoom of the camera [in Swedish Lapland], which I never do in my normal working life-l avoid it normally, but out here it seems to be the only way I can find to express distance. I only work with wide shot out here. I have done no close ups at all - at least not of the body. I have close ups of twigs and icicles and snow, but the body seems to need to remain in the distance for me. ${ }^{15}$

Whilst I have so far chosen examples of artists_-Praed, Dor, and Shalev—working in their local neighborhoods, they and Edmunds are artists who work internationally. To return to Ingold's definition of place, they are bound together in the 'knot' of their home place but not bound by it. Not knowing too much about a place can allow us to see it, and ourselves, freshly. Lippard writes, "looking at land through nonexpert eyes, we can learn a lot about our own assumptions and about the places we live in and pass through" (125).

In each case, whether produced near or far from home, these are works that tread lightly on the earth: with only a few people and a minimum of kit, usually a single camera. Ingold makes what for me is a useful distinction between 'inhabiting' and 'occupying' a place (101). Referring back to Merleau-Ponty's idea of the body as inhabiting or haunting space, making space directly available to us, I see Edmunds'approach as to inhabit, to engage with space directly through the body, contrasting with the way in which a traditional film crew would move on to location, cordoning off a particular area, controlling action, focusing light, limiting sound. Inhabiting is informed by an attention to active vision and responsiveness to place: we come back to looking around.

When Lippard writes that "a lived-in landscape becomes a place, which implies intimacy," she is defining place as seen from the inside; landscape, from the outside (7). In one of the research pieces made in Swedish Lapland, stand-in, Edmunds places performer Scott Smith in the frame, where he remains, a static figure silhouetted as a black outline against a series of different spaces, until the final shot, where he wanders off screen. Again, the attention moves in and out of place, in two sites simultaneously: where Edmunds frames place in an embodied response to the moment, it is in screen space that Smith's series of stillnesses are connected, through the edit. Edmunds has spoken of how Smith is a stand-in for herself, and also for the viewer. ${ }^{16}$ He returns our attention to the surface of the screen and his stillness anchors us in relation to the shifting landscapes against which we see him. The small, still figure on screen connects us to our sense of wonder at vastness. For Bachelard:

Immensity is within ourselves. It is attached to a sort of expansion of being that life curbs and caution arrests, but which starts again when we are alone. As soon as we become motionless, we are elsewhere; we are dreaming in a world that is immense. Indeed, immensity is the movement of motionless man. (184)

From Cornwall, to Tel Aviv, to the Arctic Circle; from domestic interiors to metropolitan streets and spaces, to vast snowy expanses. The attention to place, and to the physical experience of space, evidenced in works such as those discussed above, calls for a similar thoughtfulness in creating contexts for these works to be screened and experienced by audiences. Whilst discourses around place may sometimes abstract issues around space, in witnessing screendance we read detail and specificity into the spaces we see, drawing on our personal embodied experience. In foregrounding place, I propose that screendance can speak to our shared humanity by articulating particularity and difference, in so doing, referring us back to our own bodies and our particular perceptions of space: 
It is through the sensuous world of the body, through our eyes, ears, skin, muscles, and organs, that we see, feel and respond to all that happens. The body is the ground from which all our knowing of the world begins. (3) ${ }^{17}$

\section{Notes}

1. Merleau-Ponty, Maurice. "An Unpublished text."Trans. James M. Edie. The Primacy of Perception: And Other Essays on Phenomenological Psychology, the Philosophy of Art, History and Politics. Ed. James M. Edie. Evanston, IL: Northwestern U P, 1964. 3-11. Print.

2. Marks, Laura U. Touch: Sensuous Theory and Multisensory Media. Minneapolis: U of Minnesota P, 2002. Print.

3. Berger, John. Ways of Seeing. London: British Broadcasting Corporation \& Penguin Books, 1972. Print.

4. Nelson, Lisa. "Composition, Communication, and the Sense of Imagination: Lisa Nelson on her pre-technique of dance, the Tuning Scores." Self interview. Ballet Tanz. Critical Correspondence, April 2006. Web. 10 Feb. 2010.

5. Dance training is, of course, itself a vast subject. Here, I am referring to a particular form of training in working with body, space and site through improvisation. See the following books for further information:

- Tufnell, Miranda and Chris Crickmay. Body, Space, Image: notes toward improvisation and performance. London: Dance Books, 2008. Print.

- Cooper Albright, Ann and David Gere, eds. Taken By Surprise: A Dance Improvisation Reader. Middletown, CT: Wesleyan U P, 2003. Print.

- Blom, Lynne Anne and L. Tarin Chaplin. The Moment of Movement: Dance Improvisation. Pittsburgh and London: U of Pittsburgh P, 1998. Print.

6. Rosenberg, Douglas. "Video Space: a Site for Choreography." Essays by Douglas Rosenberg. DVPG, n.d. Web. 4 Feb. 2010.

7. Ingold, Time. Lines: A Brief History. London and New York: Routledge, 2007. Print.

8. Bench, Harmony. "Anti-Gravitational Choreographies: Strategies of Mobility in Screendance." Opensource: \{Videodance\} 2007: Proceedings of the Second Annual International Opensource: \{Videodance\} Symposium, Findhorn, Scotland, 20-24 Nov. 2007. Nairnshire, Scotland: Goat Media, 2009. 116-125. Print.

9. Lippard, Lucy R. The Lure of the Local: Senses of Place in a Multicentred Society. New York: The New Press, 1997. Print.

10. Clifford, Sue and Angela King, eds. Local Distinctiveness: Place, Particularity and Identity. London: Common Ground, 1993. Print.

11. Bachelard, Gaston. The Poetics of Space. 1958. Trans. Maria Jolas. Boston: Beacon Press, 1994. Print.

12. Dor, Shahar. Improvideo Workshop :: London, UK.: September 2007. Artness: The Work of Shahar Dor, n.d. Web. 19 Feb. 2010.

13. Balbernie, Angus. On Shaping a Walk. AgnusBalbernie.com, n.d. Web.2 Mar. 2010.

14. Edmunds, Becky. "Hybrids: Becky Edmunds." By Chirstinn Whyte. Filmwaves. Filmwaves, 10 Dec 2009. Web. 15 Dec. 2010.

15. Edmunds, Becky. cold - vision, perception, production. Becky Edmunds, Mar. 2009. Web. 15 Dec. 2010.

16. Edmunds, Becky. The Screen as a Site for Choreography Research Event, University of Bristol, UK. April 2009. Speech.

17. Tufnell, Miranda and Chris Crickmay. A widening field: journeys in body and imagination. London: Dance Books, 2004. Print. 